\title{
Body Weight Reduction Associated with the Sibutramine Treatment: Overall Results of the PRIMAVERA Primary Health Care Trial
}

\author{
Ivan Ivanovich Dedov Galina Afanasievna Melnichenko \\ Ekaterina Anatolievna Troshina Natalya Valentinovna Mazurina \\ Marina Olegovna Galieva \\ Endocrinology Research Center, Moscow, Russia
}

\section{Keywords}

Obesity $\cdot$ Overweight $\cdot$ Sibutramine $\cdot$ PRIMAVERA $\cdot$ Blood pressure $\cdot$ Adverse events

\begin{abstract}
Objective: The aim of the study was to assess the effectiveness and safety of long-term sibutramine therapy in routine clinical practice. Methods: In total, 98,774 patients $(82.3 \%$ women, $17.7 \%$ men) from 142 cities of the Russian Federation were enrolled in the PRIMAVERA program. The mean age of the patients was $39.39 \pm 10.38$ years, the mean body weight was $99.1 \pm 14.28 \mathrm{~kg}$, and the mean BMI was $35.7 \pm 4.41 \mathrm{~kg} / \mathrm{m}^{2}$. The duration of the sibutramine therapy was determined by physicians: $59.3 \%$ of patients took the drug for 6 months, the treatment course of $37.7 \%$ of patients was 12 months, and $3 \%$ of patients had treatment for 3 months. Results: The BMI reduction correlated with the treatment duration: $3.4 \pm 1.53 \mathrm{~kg} / \mathrm{m}^{2}$ after 3 months of therapy, $5.4 \pm 2.22 \mathrm{~kg} / \mathrm{m}^{2}$ after 6 months, and $7.2 \pm 3.07 \mathrm{~kg} / \mathrm{m}^{2}$ after 12 months. The body weight reduction after 3, 6 and 12 months of treatment was $9.5 \%, 15.1 \%$, and $19.7 \%$, respectively. The body weight loss associated with sibutramine treatment was accompanied by a slight decrease in blood pressure and did not lead to any significant increases of the heart rate. Conclusions: The results of the PRIMAVERA study confirmed the lack of increased risk of using sibutramine in routine clinical practice in patients without underlying cardiovascular disease and low rate of adverse events.

(c) 2018 The Author(s)

Published by S. Karger GmbH, Freiburg
\end{abstract}




\section{Introduction}

Despite the established global strategy for nutrition, physical activity and health, the number of overweight and obese people is multiplying year by year. As reported by the WHO in 2014, more than 600 million individuals (11\% of men and $13 \%$ of women) suffer from obesity. Overweight people were several-fold more widespread - more than 1.3 billion adults, or $39 \%$ of the world population [1].

Pharmacotherapy is being used to increase the number of patients who achieve clinically significant results [2]. Given that obesity is often associated with functional disorders in the hypothalamus and other centers responsible for eating behavior, as well as with certain neurotransmitter metabolism disturbances, the prescription of several centrally acting drugs seems to be well justified $[3,4]$. The only centrally acting anti-obesity drug in the Russian Federation is sibutramine.

Sibutramine has been used in routine clinical practice for more than 10 years. A metaanalysis of randomized placebo-controlled studies demonstrates that the effectiveness of obesity treatment substantially increases after sibutramine administration: The number of patients who achieved a weight reduction by $5 \%$ and $10 \%$ of their initial weight grew by $32 \%$ and $18 \%$, respectively [5]. Sibutramine therapy also has an effect on the long-term results, with a $10-30 \%$ increase in the number of persons who successfully maintain their body weight reduction ('successful' means the maintenance of $80-100 \%$ of lost weight) $[2,5]$. The metabolic effects of sibutramine include a reduction in waist circumference, a decrease in the triglyceride (TG) level, an increase of low-density lipoprotein (LDL) levels, and a lowering of glycohemoglobin (HbA1C) and fasting glycemia values in patients with type 2 diabetes mellitus (DM2) and obesity [5, 6].

The results of international trials were the basis for further development and implementation of the safety assessment system for obesity drug therapy with sibutramine [7-9]. The aims of the PRIMAVERA trial were to assess the effectiveness and safety of long-term sibutramine therapy in routine clinical practice of obesity treatment and to determine the spectrum of adverse events (AEs) recorded during sibutramine therapy.

\section{Material and Methods}

The All-Russia Non-Interventional Program of Reduxine Safety Monitoring for Weight Reduction in Patients with Alimentary Obesity in Routine Clinical Practice (PRIMAVERA trial) was carried out in the period from November 2012 to July 2015.

3,095 physicians (general practitioners, endocrinologists, gastroenterologists, gynecologists, neurologists, and cardiologists) from 142 cities and towns of Russia participated in the study. The physicians entered demographic data, anthropometric data, medication, and clinical variables in standardized documentation forms. On-site monitoring was provided by medical science liaisons from the Russian pharmaceutical company PROMOMED, the sponsor of the PRIMAVERA study. Data were entered into a separate database and were monitored by employees responsible for data evaluation. The observational program was registered by the Ministry of Health of the Russian Federation, approved by the Independent Interdisciplinary Committee for Ethical Review of Clinical Trials on October 12, 2012 (Protocol No.16) in accordance with the Principles of Good Clinical Practice, and registered in the international register for clinical trials (ClinicalTrials.gov NCT01773733).

The statistical analysis of data was carried out using SPSS 17.0.0 (IBM, Armonk, NY, USA). For the purpose of effectiveness and safety parameters, the statistical significance of changes was tested on the basis of nonparametric methods, i.e. the Wilcoxon Signed Rank test. The data were analyzed both within the Intentto-Treat (ITT) population and in separate groups with comorbidities. Data are presented as mean \pm SD, median, minimum, maximum, and frequencies in percent. 
Table 1. Baseline characteristics of the included patients $(\mathrm{n}=$ 69,810 )
Dedov et al.: Body Weight Reduction Associated with the Sibutramine Treatment: Overall Results of the PRIMAVERA Primary Health Care Trial

\begin{tabular}{lll}
\hline Value & $\mathrm{M} \pm \mathrm{SD}$ & Min-max \\
\hline Body weight, kg & $99.1 \pm 14.28$ & $56-200$ \\
Body height, cm & $166.7 \pm 7,48$ & $140-210$ \\
BMI, kg/m ${ }^{2}$ & $35.7 \pm 4.41$ & $20.7-73.7$ \\
Waist circumference, cm & $105.7 \pm 13.71$ & $61-201$ \\
SBP, mm Hg & $122.49 \pm 9.75$ & $80-198$ \\
DBP, mm Hg & $77.42 \pm 7.78$ & $50-121$ \\
HR, BPM & $72.94 \pm 6.93$ & $46-130$ \\
\hline
\end{tabular}

The total number of patients amounted to 98,774. 5,461 patients ended their participation in the program at the screening stage because of contraindications to sibutramine treatment, including 4,696 who were not included because of cardiovascular risk. All enrolled patients who took at least one dose of the study drug were subject to safety monitoring. The safety evaluation population involved 93,313 patients. 25.2\% of the case report forms were not included in the evaluation process due to incorrect completion of the assessed parameters.

The statistical analysis related to 69,810 case report forms of patients who were considered as the therapy effectiveness population. The study population comprised of $82.3 \%(57,456)$ women and $17.7 \%$ $(12,354)$ men. The mean age of patients was $39.39 \pm 10.376$ years; the cohort included mainly patients of the middle age group: $25-39$ years (46.3\%) and 40-54 years (38.2\%) (table 1). 55\% of patients had comorbidities that had been diagnosed before they were enrolled in the study. The main registered comorbidities were as follows: DM2 $-18.8 \%$ of patients $(13,155)$, arterial hypertension $(\mathrm{AH})$ controlled by antihypertensive drugs $-6.5 \%$ of patients $(4,537)$, dyslipidemia $-4.8 \%$ of patients $(3,337)$, impaired fasting glucose or impaired glucose tolerance $-3.3 \%$ of patients $(2,333)$, joint diseases (osteoarthrosis, spondylosis) $-3.3 \%$ of patients $(2,330)$, gynecological disorders (uterine fibroids, polycystic ovary syndrome, ovarian dysfunction, infertility, endometrial hyperplasia) $-9.8 \%$ of patients $(6,871)$, gastrointestinal diseases $-1.2 \%$ of patients (839), others $-4.0 \%$ of patients $(2,803)$.

All decisions concerning treatment duration and withdrawal were made according to the package insert by physicians or by patients themselves. The mean course of sibutramine therapy was 8.1 months. 26,263 patients $(37.7 \%)$ completed the 12-month therapy course; most of the patients took the drug for 6 months $(41,431$ patients $(59.3 \%))$, while the remaining 2,116 patients $(3 \%)$ took it for 3 months.

\section{Results}

\section{Anthropometric Parameters}

Weight, BMI, and waist circumference before and after treatment were analyzed to assess the effectiveness of sibutramine. The diagnosis of obesity was no longer applicable to 17,663 patients $(25.3 \%)$ after just a 3-month course of treatment; this category moved to overweight. In the course of the program, $14.1 \%$ of patients achieved normal body weight (BMI $<25$ $\mathrm{kg} / \mathrm{m}^{2}$ ). The degree of obesity assessed by BMI was reduced in $23.5 \%$ of patients, and morbid obesity (BMI $>40 \mathrm{~kg} / \mathrm{m}^{2}$ ) was eliminated in $12.6 \%$ of patients.

The positive effect on body weight resulted in a mean BMI reduction of $3.4 \pm 1.53 \mathrm{~kg} / \mathrm{m}^{2}$ $(9.5 \pm 4.28 \mathrm{~kg}$ on average) after 3 months of treatment. After 6 months of treatment, the mean BMI reduction was $5.4 \pm 2.22 \mathrm{~kg} / \mathrm{m}^{2}(15.0 \pm 6.22 \mathrm{~kg})(\mathrm{p}<0.001)$. The BMI reduction in the 12 -month treatment group was 2.12 times higher and amounted to $7.2 \pm 3.07 \mathrm{~kg} / \mathrm{m}^{2}(20.0 \pm$ $8.62 \mathrm{~kg})(\mathrm{p}<0.001)$. (fig. 1).

The mean waist circumference decreases after 3,6 and 12 months of therapy were $6.3 \pm$ $4.31 \mathrm{~cm}, 10.6 \pm 6.30 \mathrm{~cm}$ and $16.0 \pm 8.94 \mathrm{~cm}$, respectively. Tables 2 and 3 demonstrate the impact of the sibutramine treatment on body weight and waist circumference, depending on the comorbidities present. 
Dedov et al.: Body Weight Reduction Associated with the Sibutramine Treatment: Overall Results of the PRIMAVERA Primary Health Care Trial

Table 2. Results of sibutramine therapy in patients split by BMI category

\begin{tabular}{|c|c|c|c|c|}
\hline Treatment duration & BMI $25-29.9 \mathrm{~kg} / \mathrm{m}^{2}$ & BMI $30-34.9 \mathrm{~kg} / \mathrm{m}^{2}$ & BMI $35-39.9 \mathrm{~kg} / \mathrm{m}^{2}$ & $\mathrm{BMI}>40 \mathrm{~kg} / \mathrm{m}^{2}$ \\
\hline \multicolumn{5}{|l|}{3 months } \\
\hline Body weight loss, kg & $-7.13 \pm 3.10^{*}$ & $-8.54 \pm 3.39$ & $-9.97 \pm 4.2$ & $-11.94 \pm 5.72$ \\
\hline Body weight change, $\%$ & $-8.75 \pm 3.79$ & $-9.32 \pm 3.60$ & $-9.72 \pm 3.95$ & $-10.05 \pm 4.5$ \\
\hline BMI change, $\mathrm{kg} / \mathrm{m}^{2}$ & $-2.51 \pm 1.09$ & $-3.05 \pm 1.19$ & $-3.61 \pm 1.48$ & $-4.37 \pm 2.06$ \\
\hline \multicolumn{5}{|l|}{6 months } \\
\hline Body weight loss, kg & $-10.71 \pm 4.21$ & $-13.35 \pm 4.87$ & $-15.97 \pm 6.07$ & $-19.03 \pm 7.88$ \\
\hline Body weight change, $\%$ & $-13.07 \pm 4.99$ & $-14.56 \pm 5.13$ & $-15.56 \pm 5.67$ & $-16.02 \pm 6.34$ \\
\hline BMI change, $\mathrm{kg} / \mathrm{m}^{2}$ & $-3.75 \pm 1.45$ & $-4.77 \pm 1.71$ & $-5.78 \pm 2.13$ & $-6.96 \pm 2.82$ \\
\hline \multicolumn{5}{|l|}{12 months } \\
\hline Body weight loss, kg & $-12.93 \pm 5.05$ & $-16.84 \pm 6.05$ & $-21.10 \pm 7.96$ & $-26.13 \pm 10.99$ \\
\hline Body weight change, $\%$ & $-15.7 \pm 5.9$ & $-18.26 \pm 6.29$ & $-20.46 \pm 7.38$ & $-21.90 \pm 8.85$ \\
\hline BMI change, $\mathrm{kg} / \mathrm{m}^{2}$ & $-4.5 \pm 1.71$ & $-6.0 \pm 2.11$ & $-7.61 \pm 2.80$ & $-9.52 \pm 3.89$ \\
\hline
\end{tabular}

* Data are presented as the mean \pm SD.

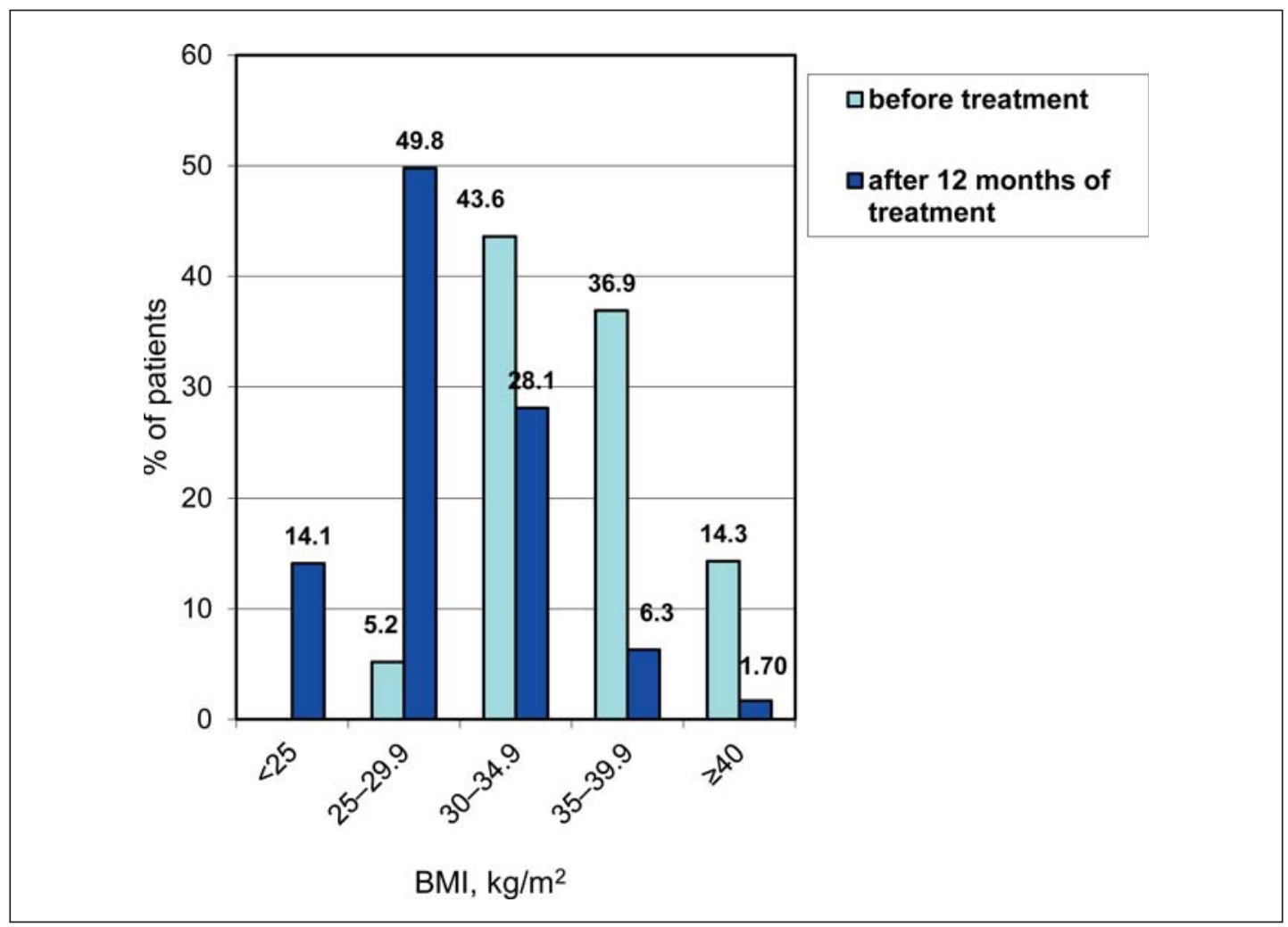

Fig. 1. Distribution of patients' BMI before treatment and after 12 months of therapy.

An analysis of comorbidities was carried out in order to assess the impact of long-term sibutramine therapy on cardiovascular variables in patients with an increased risk of AEs.

Therefore, the positive effect of sibutramine treatment in patients without contraindications depends on the therapy duration and showed no direct correlation with comorbid diseases. 
Table 3. Body weight loss (kg) and body weight change (\%) in subgroups of patients with different comorbidities and different sibutramine therapy duration

\begin{tabular}{llll}
\hline Reported comorbidities & \multicolumn{2}{l}{ Duration of the therapy } & \\
\cline { 2 - 4 } & 3 months & 6 months & 12 months \\
\hline DM2 & $-9.0 \pm 4.19(8.8 \%)$ & $-14.4 \pm 5.90(14.0 \%)$ & $-19.2 \pm 8.25(18.1 \%)$ \\
Joint diseases & $-8.7 \pm 4.21(8.4 \%)$ & $-15.1 \pm 6.12(14.4 \%)$ & $-23.4 \pm 8.92(21.3 \%)$ \\
Metabolic syndrome components* & $-9.4 \pm 4.15(9.3 \%)$ & $-15.3 \pm 6.03(15.1 \%)$ & $-20.5 \pm 7.76(20.0 \%)$ \\
Gynecological disorders & $-9.8 \pm 3.94(10.3 \%)$ & $-15.4 \pm 5.81(16.1 \%)$ & $-20.1 \pm 7.64(20.9 \%)$ \\
\hline
\end{tabular}

* DM2 impaired glucose tolerance, metabolic syndrome, dyslipidemia, hypertriglyceridemia, hypercholesterinemia, non-alcoholic fatty liver disease, controlled arterial hypertension.

One of the purposes of the PRIMAVERA study was to determine the optimal duration of the therapy. It was shown that 45,016 patients $(64.5 \%)$ reached a clinically relevant weight loss of $\geq 10 \%$ after 6 months. Moreover, 11,846 (17.5\%) of them lost $\geq 20 \%$ of their initial weight. A subgroup of patients, who achieved a clinically significant weight loss but did not approach the target values, continued the therapy for a total of 12 months. The result of 1 year of therapy was a clinically significant weight loss in 26,263 patients $(37.7 \%): 10-20 \%$ in 13,683 patients $(52.1 \%)$ and $\geq 20 \%$ in 11,057 patients $(42.1 \%)$.

\section{Cardiovascular Parameters}

The control of cardiovascular risk is the most important item in sibutramine safety monitoring. In the PRIMAVERA trial, stringent cardiovascular parameter monitoring was scheduled every 2 weeks during the first 3 months of treatment, monthly during months $4-6$ of treatment, and every 3 months for the following therapy period. If an increase in systolic (SBP) or diastolic (DBP) blood pressure by more than $10 \mathrm{~mm}$ Hg at two consecutive visits or an increase in blood pressure (BP) to $145 / 90 \mathrm{~mm} \mathrm{Hg}$ or more, or a heart acceleration of more than 10 $\mathrm{BPM}$ was reported, it was recommended to discontinue the drug. A single increase in SBP or DBP of more than $10 \mathrm{~mm} \mathrm{Hg}$ or a HR increase of up to $10 \mathrm{BPM}$ between any two visits was registered in 18,151 patients (26\%). An increase in these variables at two consecutive visits throughout the therapy period was recorded in $2.57 \%$ of patients $(1,794)$, mostly during the first 3 months of treatment. The analysis of BP and HR revealed that they did not change significantly either in patients who completed a 3-month therapy course or in patients who took sibutramine for 6 months or 1 year. HR remained stable after the 3rd, 6th and 12th month of treatment (mean $\Delta+0.22 \mathrm{BPM},-0.37 \mathrm{BPM}$ and $-0.86 \mathrm{BPM}$, respectively). These variables are within the margin of error. Therefore, we conclude that this sibutramine treatment does not lead to any decline in HR values. As for BP, a clinically non-significant decrease in SBP and DBP occurred during both 6 and 12 months of treatment. At the same time, a more apparent weight reduction had a more significant positive effect on the BP. The average SBP and DBP reduction during 12 months of therapy was -2.36 and $-2.09 \mathrm{~mm} \mathrm{Hg}$, respectively ( $p<0.001$ ) (fig. 2).

We analyzed the therapy results in patients who had metabolic disorders related to obesity such as DM2, impaired glucose tolerance, metabolic syndrome, dyslipidemia, hypertriglyceridemia, hypercholesterinemia, non-alcoholic fatty liver disease, and controlled arterial hypertension. Weight reduction after long-term (over 6 months) sibutramine treatment in the subgroup of patients with a high cardiometabolic risk (patients with DM2 and metabolic problems) was also accompanied by a decrease in SBP $(\Delta=-1.75 \mathrm{~mm} \mathrm{Hg})$ and $\operatorname{DBP}(\Delta=-1.52 \mathrm{~mm} \mathrm{Hg})$ and did not result in an HR increase $(\Delta=-0.28 \mathrm{BPM})$. 
Dedov et al.: Body Weight Reduction Associated with the Sibutramine Treatment: Overall Results of the PRIMAVERA Primary Health Care Trial

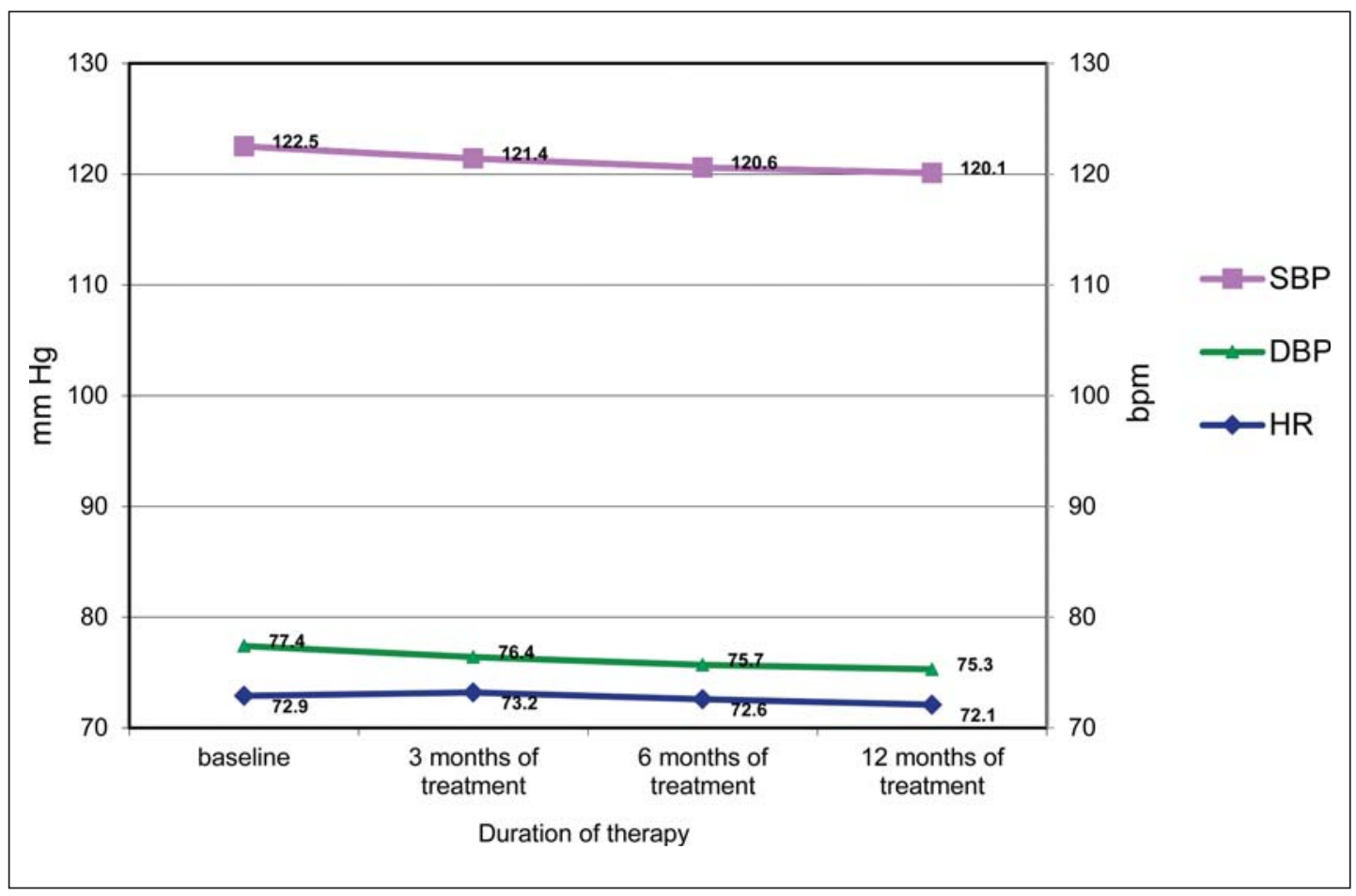

Fig. 2. SBP, DBP and HR, by duration of sibutramine therapy.

Sibutramine has demonstrated its high tolerability during both 6 and 12 months of therapy. The total number of patients with AEs amounted to 2,903 (3.2\%). In $42 \%$ of these patients $(1,219,1.7 \%$ of the whole study group), these AEs were probably or definitely linked to sibutramine treatment according to the rating of the physicians, and a possible link (i.e. other causes are also conceivable) was assumed in $36 \%(1,045,1.5 \%$ of the whole study group). We registered no serious AEs related to drug intake. Single non-repeating AEs (29\%) accounted for most of the AEs observed. Their percentages were as follows : dry mouth $39.0 \%$, headaches $22.0 \%$, insomnia $19.5 \%$, BP increase $7.3 \%$, change in mood $7.3 \%$, and tachycardia $4.9 \%$. As a rule, these events were mild and decreased with the continuation of drug administration. The AEs that arose led to the dropout of only 127 patients $(0.18 \%)$. The overwhelming majority of patients had no need to discontinue the drug because of AEs.

Thus, the results obtained from the PRIMAVERA observational program confirmed the lack of an increased risk in patients without contraindications and a low rate of AEs in routine clinical practice.

\section{Discussion}

The analysis of the PRIMAVERA program results, which included an ITT population of 69,810 patients taking sibutramine in routine clinical practice, demonstrates that clinically significant results (a weight reduction $\geq 5 \%$ ) were achieved in $92.5 \%$ of cases.

The acceptance of the disease's chronicity and the necessity of continuous treatment form the basis of the modern approach to obesity therapy. All national and international clinical guidelines for obesity treatment insist on the importance of behavior therapy, enabling the patients to develop and reinforce new skills in eating behavior [10-13]. In order to achieve 
the desired effects, it is essential to change lifestyle habits, which includes dietary treatment and increasing physical activity. However, changing lifestyle to successfully reduce body mass requires high efforts from patients that are not always achievable in real clinical practice, which results in poor effectiveness of treatment: not more than $10 \%$ of obese people are able to obtain the intended effects in response to conventional therapy [14-18]. A long-term observation has shown that, despite various weight improvement programs which included diet therapy and physical exercise, there was not only no weight reduction over 10 years, but body weight actually increased by $1.6-2 \%$ on average [14-18].

Monitoring of therapy effectiveness is an important part of the algorithm for monitoring the use of anti-obesity drugs. The first month of treatment was the point for the first effectiveness control. The treatment was considered to be primary effective in the event of weight reduction of $\geq 2 \mathrm{~kg}$ within a month. The results obtained demonstrate a high level of therapy response: 49,941 patients (71.5\%) passed the $2 \mathrm{~kg}$ threshold. The next effectiveness control took place after 3 months of treatment, when a loss of $\geq 5 \%$ of the initial weight was considered a positive result. In 64,574 cases (92.5\%) weight loss over $5 \%$ was achieved after 3 months of sibutramine therapy. Other studies on sibutramine in primary care medicine report $5 \%$ weight reduction in $57-77 \%$ of cases $[8,19,20]$. According to the results of a meta-analysis of double-blind placebo-controlled weight loss studies, sibutramine treatment increased the absolute percentage of $5 \%$ and $10 \%$ responders by $32 \%$ and $18 \%$, respectively [5]. Our study was not randomized, and it may explain the significantly higher rate of therapy responders.

According to the package insert, it is recommended to withdraw sibutramine in order to reduce therapy risks if there is no $5 \%$ weight loss during 3 months of treatment. In our study, only $2,116(3 \%)$ of $5,236(7.5 \%)$ non-responders discontinued the drug after 3 months. Dose adjustment (10 or $15 \mathrm{mg}$ ) and therapy duration were at the physician's discretion in accordance with the therapy results and the level of the patient's satisfaction. It is important to note that there were no significant differences between the therapy results of with 10 and $15 \mathrm{mg}$. We assume that individual attributes of patients were the determining factors.

Another important point concerning sibutramine therapy is weight regain, i.e. an increase in body mass over $3 \mathrm{~kg}$ compared with the previously reached result. Among the responders to the treatment (based on results after 3 months), weight regain during the treatment course was reported in only $0.41 \%$ of cases. A patient's lack of compliance can be a possible reason for weight regain. Results of previous studies have shown that patients treated with sibutramine achieved successful weight maintenance $10-30 \%$ more frequently than those given a placebo medication (successful weight maintenance defined as maintaining $80-100 \%$ of the initial weight loss) $[7,8,21]$. This observation is, however, limited by the varying definitions of weight maintenance between the studies. Moreover, the studies by Mathus-Vliegen et al. [7] and by Apfelbaum et al. [21] assessed weight maintenance after a period of very-low-calorie diets.

Thus, we can recommend at least a 6-month course of sibutramine therapy to reach a sufficient body weight reduction of more than $10 \%$ and to maintain the attained result. The possibility and reasonableness of the treatment's extension up to 12 months depends on the results. In previous studies, according to the results of magnetic resonance imaging, it was shown that the reduction in waist circumference in patients undergoing sibutramine therapy occurred thanks to reducing the amount of both subcutaneous and visceral fat in the abdominal area [22]. As demonstrated in the present study, the results of sibutramine therapy depend on its duration. Taking into account the role of visceral fat in the development of metabolic complications, this results also make longer therapy (up to 12 months) a reasonable choice.

The SCOUT trial evaluated the incidence of cardiovascular disease and death among highrisk subjects who participated in diet and exercise programs [9]. As our study was a primary health care trial, sibutramine was already contraindicated in patients with pre-existing cardiovascular disease. Under primary care conditions, no serious AE was registered, and 
sibutramine therapy proved to be safe. A high tolerability of the drug was demonstrated - the total number of AEs in the course of 6-12 months of treatment does not exceed 3.2\%. Weight loss is recommended in all major guidelines for antihypertensive therapy [22, 23]. As sibutramine is effective in managing obesity, it helps to prevent the clinical consequences of obesity and cardiovascular disease risk factors.

A favorable safety profile of sibutramine and the absence of any influence on ambulatory $\mathrm{BP}$ and HR in patients without cardiovascular diseases were confirmed in our study. Most studies showed no or only minimal changes in SBP, but a modest increase in DBP [24-27]. In patients who experience a clinically significant and sustained increase in blood pressure, the drug should be discontinued [24, 28].

The results of a large cohort study focused on obesity treatment in the UK were published in May 2015 [29]. A cohort of patients with weight loss medication was analyzed: 23,927 patients took sibutramine, and 77,047 took orlistat. Sibutramine therapy was associated with an insignificant increase in the incidence of myocardial infarction and cerebral circulation disorders, but only in those patients who already had a history of ischemic heart disease and cerebrovascular disturbances (hazard ratio 1.69, 95\% CI 1.12-2.56). The overall mortality in the group of patients who took sibutramine did not differ from that of the orlistat group (hazard ratio $0.67,95 \%$ CI $0.34-1.32$ ). It was confirmed that sibutramine administration to patients without cardiovascular diseases is not associated with a risk of infarctions or cerebral circulation disorders. Thus it was concluded that permission for sibutramine use in patients without cardiovascular diseases was inappropriately withdrawn.

\section{Acknowledgments}

We are indebted to all participants of the study from 142 cities and towns of the Russian Federation. Special thanks to Advisory Board members: Ivan Ivanovich Dedov, Galina Afanasievna Melnichenko, Ashot Musayelovich Mkrtumyan, Marina Vladimirovna Zhuravleva, Tatyana Ivanovna Romantsova, Elena Nikolaevna Yuschsyuk, Elena Alekseevna Volskaya, Ekaterina Anatolievna Troshina, and Fatima Hadzhimuratovna Dzgoeva.

\section{Disclosure Statement}

PRIMAVERA study was supported by PROMOMED Company

Advisory board members did not get any contribution for development of the study protocol, monitoring of the study, and study results report. The authors were not granted for writing this manuscript. Endocrinology Research Center receives contributions from PROMOMED Company as a part of cooperation in scientific and educational fields.

\section{References}

1 World Health Organization: Overweight and Obesity. Fact Sheet N 311. available at www.who.int/mediacentre/factsheets/fs311/en/ (last accessed July 25, 2018):

2 Karam J, McFarlane S: Tackling obesity: new therapeutic agents for assisted weight loss. Diabetes Metab Syndr Obes 2010;3:95-112.

3 Yeo G, Heisler L: Unraveling the brain regulation of appetite: lessons from genetics. Nat Neurosci 2012;15: 1343-1349.

4 Lam D, Garfield A, Marston O, Shaw J, Heisler LK: Brain serotonin system in the coordination of food intake and body weight. Pharmacol Biochem Behav 2010;97:84-91.

5 Rucker D, Padwal R, Li SK, Curioni C, Lau DCW: Long term pharmacotherapy for obesity and overweight: updated meta-analysis. BMJ 2007;335:1194-1199.

6 Zhou YH, Ma XQ, Wu C, Lu J, Zhang SS, Guo J, Wu SQ, Ye XF, Xu JF, He J: Effect of anti-obesity drug on cardiovascular risk factors: a systematic review and meta-analysis of randomized controlled trials. PLoS One 2012; 7:e39062. 
7 Mathus-Vliegen EM: Long-term maintenance of weight loss with sibutramine in a GP setting following a specialist guided very-low-calorie diet: a double-blind, placebo-controlled, parallel group study. Eur J Clin Nutr 2005;59(suppl 1):S31-38. discussion S39.

8 James W, Astrup A, Finer N, Hilsted J, Kopelman P, Rössner S, Saris WH, Van Gaal LF: Effect of sibutramine on weight maintenance after weight loss: a randomised trial. STORM Study Group. Sibutramine Trial of Obesity Reduction and Maintenance. Lancet 2000;356:2119-2125.

9 James W, Caterson I, Coutinho W, Finer N, Van Gaal LF, Maggioni AP, Torp-Pedersen C, Sharma AM, Shepherd GM, Rode RA, Renz CL; SCOUT Investigators: Effect of sibutramine on cardiovascular outcomes in overweight and obese subjects. N Engl J Med 2010;363:905-917.

10 Garvey WT, Mechanick JI, Brett EM, Garber AJ, Hurley DL, Jastreboff AM, Nadolsky K, Pessah-Pollack R, Plodkowski R; Reviewers of the AACE/ACE Obesity Clinical Practice Guidelines: American Association of Clinical Endocrinologists and American College of Endocrinology Comprehensive Clinical Practice Guidelines for Medical Care of Patients with Obesity. Endocr Pract 2016;22(suppl 3):1-203.

11 Yumuk V, Tsigos C, Fried M, Schindler K, Busetto L, Micic D, Toplak H; Obesity Management Task Force of the European Association for the Study of Obesity: European guidelines for obesity management in adults. Obes Facts 2015;8:402-424.

12 Apovian C, Aronne L, Bessesen H, McDonnell ME, Murad MH, Pagotto U, Ryan DH, Still CD; Endocrine Society: Pharmacological management of obesity: an Endocrine Society Clinical Practice Guideline J Clin Endocrinol Metab 2015; 100:342-362.

13 Jensen M, Ryan D, Apovian C, Ard JD, Comuzzie AG, Donato KA, Hu FB, Hubbard VS, Jakicic JM, Kushner RF, Loria CM, Millen BE, Nonas CA, Pi-Sunyer FX, Stevens J, Stevens VJ, Wadden TA, Wolfe BM, Yanovski SZ, Jordan HS, Kendall KA, Lux LJ, Mentor-Marcel R, Morgan LC, Trisolini MG, Wnek J, Anderson JL, Halperin JL, Albert NM, Bozkurt B, Brindis RG, Curtis LH, DeMets D, Hochman JS, Kovacs RJ, Ohman EM, Pressler SJ, Sellke FW, Shen WK, Smith SC Jr, Tomaselli GF; American College of Cardiology/American Heart Association Task Force on Practice Guidelines; Obesity Society: 2013 AHA/ACC/TOS Guideline for the Management of Overweight and Obesity in Adults: a report of the American College of Cardiology/American Heart Association Task Force on Practice Guidelines and The Obesity Society. Circulation 2014;129(25 suppl 2):S102-138.

14 Anderson JW, Konz EC, Frederich RC, Wood CL: Long-term weight-loss maintenance: a meta-analysis of US studies. Am J Clin Nutr 2001;74:579-584.

15 Avenell A, Brown TJ, McGee MA, Campbell MK, Grant AM, Broom J, Jung RT, Smith WC: What are the long-term benefits of weight reducing diets in adults? A systematic review of randomized controlled trials. J Hum Nutr Diet 2004;17:317-335.

16 Orzano AJ, Scott JG: Diagnosis and treatment of obesity in adults: an applied evidence based review. J Am Board Fam Pract 2004;17:359-369.

17 Douketis JD, Macie C, Thabane L, Williamson DF: Systematic review of long-term weight loss studies in obese adults: clinical significance and applicability to clinical practice. Int J Obes (Lond) 2005;29:1153-1167.

18 Summerbell CD, Cameron C, Glasziou PP: Advice on low-fat diets for obesity. Cochrane Database Syst Rev 2008;3:CD003640.

19 Hauner H, Meier M, Wendland G, Kurscheid T, Lauterbach K; Study Group SA; SAT Study Weight reduction by sibutramine in obese subjects in primary care medicine: the SAT Study. Exp Clin Endocrinol Diabetes 2004; 112:201-207.

20 Smith I, Goulder M: Randomized placebo-controlled trial of long-term treatment with sibutramine in mild to moderate obesity. J Fam Pract 2001;50:505-512.

21 Apfelbaum M, Vague P, Ziegler O, Hanotin C, Thomas F, Leutenegger E: Long-term maintenance of weight loss after very-low-calorie diet: a randomized blinded trial of the efficacy and tolerability of sibutramine. Am J Med 1999;106:179-184.

22 Douketis JD, Sharma AM: Obesity and cardiovascular disease: pathogenic mechanisms and potential benefits of weight reduction. Semin Vasc Med 2005;5:25-33.

23 Bodary PF, Iglay HB, Eitzman DT: Strategies to reduce vascular risk associated with obesity. Curr Vasc Pharmacol 2007;5:249-258.

24 Scheen A: Sibutramine on cardiovascular outcome. Diabetes Care 2011;34(suppl 2):S 114-119.

25 Kim SH, Lee YM, Jee SH, Nam CM: Effect of sibutramine on weight loss and blood pressure: a meta-analysis of controlled trials. Obes Res 2003;11:1116-1123.

26 Horvath K, Jeitler K, Siering U, Stich AK, Skipka G, Gratzer TW, Siebenhofer A: Long-term effects of weightreducing interventions in hypertensive patients: systematic review and meta-analysis. Arch Intern Med 2008; 168:571-580.

27 Johansson K, Sundström J, Neovius K, Rössner S, Neovius M: Long-term changes in blood pressure following orlistat and sibutramine treatment: a meta-analysis. Obes Rev 2010;11:777-791.

28 Florentin M, Liberopoulos EN, Elisaf MS: Sibutramine-associated adverse effects: a practical guide for its safe use. Obes Rev 2008;9:378-387.

29 Hayes J.F, Bhaskaran K, Batterham R, Smeeth L, Douglas I: The effect of sibutramine prescribing in routine clinical practice on cardiovascular outcomes: a cohort study in the United Kingdom. Int J Obes (Lond) 2015; 39:1359-1364. 